\title{
STRUCTURALLY CONSTRAINED ROBUST OPTIMAL CONTROL
}

\section{CONTROL ÓPTIMO ROBUSTO CON RESTRICCIONES ESTRUCTURALES}

\author{
Héctor Peña M. ${ }^{1} \quad$ Sergio Mora C. ${ }^{1}$ \\ Recibido 17 de marzo de 2006, aceptado 23 de octubre de 2006 \\ Received: March 17, 2006 Accepted: October 23, 2006
}

\begin{abstract}
RESUMEN
Se presenta una solución al problema del control óptimo robusto, sujeto a una ley de control con restricciones de realimentación local de estados. Se muestran los resultados obtenidos por simulación, como medio de validar la propuesta, para incertezas en la matriz de planta del tipo ajustadas y no ajustadas.

Palabras clave: Control óptimo, robustez, restricciones estructurales, incertezas, realimentación.

ABSTRACT

A solution to the robust optimal control problem, subject to local states constraints in the feedback law, is presented. Examples with matched and unmatched uncertainty in the system matrix are presented. Results obtained through simulation are shown as a means of validating the proposal.
\end{abstract}

Keywords: Optimal control, robustness, structural constraints, uncertainties, feedback.

\section{INTRODUCTION}

In addition to the possibility of shaping the response of a system, the use of feedback allows several other properties to be satisfied, such as robustness, that is, the ability of a system to maintain performance in the face of uncertainties and perturbations. Normally the parameters of the open loop dynamics are not well known, and in many practical applications the controller must yield acceptable performance not only for the nominal design conditions but also within some acceptable region about this nominal. Thus, any control system design methodology must include this properties as objectives in the design procedure. This is then a fundamental problem in control theory and, as such, an area of active research. Usually the approach is the direct solution of the problem as in the $\mathrm{H}_{\infty}$ or LMI techniques [4-7]. On the other hand and for large scale linear systems, the solution of the optimal control problem renders control laws as a function of all the states of the system. This solution is not keen to practical application even though it presents the desirable characteristic related to the stabilisation property it delivers. Control structure constraints such as decentralization, that is, the formation of a control law function of local states, or of all subsystems outputs or of only local outputs, has been extensively researched. In particular in [3] a solution to this problem is given in which through a simple procedure, a feedback law that includes constraints is obtained. In this paper the problem of robustness is translated to an optimal control framework as in [1] and solved through a technique that considers structural constraints, such as feeding back only local states for a local control signal [3].

\section{OPTIMAL CONTROL APPROACH TO ROBUST DESIGN}

Let the system be represented by the following state space model

$$
\begin{aligned}
& \dot{x}=A(p) x+B u \\
& y=C x
\end{aligned}
$$

where $x \in \mathfrak{R}^{n}, y \in \mathfrak{R}^{q}$ and $u \in \mathfrak{R}^{m} . \mathrm{A}, \mathrm{B}$, and $\mathrm{C}$ are matrices of appropriate dimensions. $p \in P$ is an uncertain parameter. In [1] it is shown that for a matched uncertainty, that is, the uncertainty in $\mathrm{A}$ is in the range of $\mathrm{B}$, and for

1 Escuela de Ingeniería Eléctrica. Pontificia Universidad Católica de Valparaíso. Valparaíso-Chile. hpena@ucv.cl 
$p_{0} \in P$ being a nominal value, there exists a mxn matrix $\phi(p)$ such that

$$
A(p)-A\left(p_{0}\right)=B \phi(p)
$$

allows the determination of an asymptotically stable solution for all $p_{0} \in P$ with a feedback law $u=-K x$ for the system. To this end the LQR problem is stated as finding, for the nominal system

$$
\dot{x}=A\left(p_{0}\right) x+B u
$$

a control law $u=-K x$ that minimizes the cost functional

$$
J=\int_{0}^{\infty}\left(x^{T} F x+x^{T} Q x+u^{T} R u\right) d t
$$

where $\mathrm{F}$ is the following infimum given by

$$
F=\inf \left\{F^{\prime}:(\forall p \in P) F^{\prime} \geq \phi(p)^{T} \phi(p)\right\}
$$

If the uncertainty is unmatched, then it is decomposed into a sum of a matched and an unmatched component by projecting it into the range of $\mathrm{B}$. The proof that the solution to this problem renders a stable feedback for all $\mathrm{p}_{0} \in \mathrm{P}$, is omitted and can be found in [1].

\section{CONTROL CONSTRAINTS}

Suppose that the state and control are partitioned as

$$
x^{T}=\left[x_{1}^{T}, \ldots, x_{n}^{T}\right] \text { and } u^{T}=\left[u_{1}^{T}, \ldots, u_{n}^{T}\right]
$$

where $x_{i} \in \mathfrak{R}^{n_{i}}$ and $u_{i} \in \mathfrak{R}^{m_{i}}$, represent an interconnected dynamic system composed of $n$ subsystems with local state and control variables. The constraint given by the partition above corresponds with a decentralized state feedback, that is

$$
u(x)^{T}=\left[u_{1}\left(x_{1}\right)^{T}, \ldots, u_{n}\left(x_{n}\right)^{T}\right]
$$

meaning that any local control only depends on each local state vector. This is tantamount to saying that the optimal feedback gain ought to be expressed as

$$
K=\left[\begin{array}{cccc}
k_{1} & 0 & 0 & 0 \\
0 & k_{2} & 0 & 0 \\
. . & . . & . . & . . \\
0 & 0 & 0 & k_{n}
\end{array}\right]
$$

where $k_{i} \in \mathfrak{R}^{m_{i} x n_{i}}$. This constraint can be written in general as

$$
K-\operatorname{diag}\left\{k_{i}\right\}=0
$$

where $\operatorname{diag}\{\cdot\}$ is used to denote a diagonal matrix. Equation (6) can be expressed as a matrix function

$$
F(K)=0
$$

representing the constraint law.

\section{Theorem 1 [3]}

Let $K \in \Re^{m x n}$ be such that

$$
K+L=R^{-1} B^{T} S
$$

where $L \in \mathfrak{R}^{m x n}$ is an arbitrary matrix and $\mathrm{S}$ is a symmetric, definite positive solution matrix to the Generalized Riccati Equation

$$
A^{T} S+S A-S B R^{-1} B^{T} S+Q+L^{T} R L=0
$$

then $\sigma(A-B K) \in C^{-}$.

Proof: Since $\mathrm{S}>0$, consider $V(x)=x^{T} S x$ as a Lyapunov candidate associated to the closed loop system. Then

$$
\dot{V}(x)=x^{T}\left((A-B K)^{T} S+S(A-B K)\right) x
$$

it follows then :

$$
\begin{aligned}
\dot{V}(x) & =x^{T}\left(-Q-L^{T} R L-S B R^{-1} B^{T} S+L^{T} B^{T} S+S B L\right) x \\
& =-x^{T}\left(Q+K^{T} R K\right) x \\
& <0
\end{aligned}
$$

What has been done is really a parameterisation on $L \in \mathfrak{R}^{m \times n}$.This matrix can be defined in order to get a feasible gain $K \in \Omega$.This choice should be done 
considering that $K=R^{-1} B^{T} S-L \in \Omega$. Actually we are trying to minimize the norm of $\mathrm{L}$ in view that with $\mathrm{L}=0$ we have the optimal feedback gain of the LQR problem. That is, we must solve:

$$
\min \left(\|L\|_{e}^{2} \mid\left(R^{-1} B^{T} S-L\right) \in \Omega\right)
$$

For the constraints under consideration, the solution to the minimization problem yields [3]

$$
L=F\left(R^{-1} B^{T} P\right)
$$

That is, $\mathrm{L}$ is the matrix that accounts for the constraint to be imposed over the feedback control law (Equation (6)).

\section{CONSTRAINED ROBUST CONTROL}

If the robust control for a matched uncertainty and the constrained control are to be satisfied simultaneously, the problem is finding a feedback control law $u=\operatorname{diag}\left\{k_{i}\right\} x$ for system (1) such that the following cost functional is minimized

$$
J=\int_{0}^{\infty}\left(x^{T}\left(F+Q+L^{T} R L\right) x+u^{T} R u\right) d t
$$

where $K=R^{-1} B^{T} P$, and $\mathrm{P}>0$ is a solution to the following generalized Ricatti equation:

$$
A^{T} S+S A-S B R^{-1} B^{T} S+Q+F+L^{T} R L=0
$$

For the case of unmatched uncertainty the problem is to find control laws $u=\operatorname{diag}\left\{k_{i}\right\} x$ and $v=\operatorname{diag}\left\{z_{i}\right\} x$ for the auxiliary system:

$$
\dot{x}=A\left(p_{0}\right) x+B u+r^{-1}\left(I-B B^{+}\right) v
$$

such that the cost functional

$$
J=\int_{0}^{\infty}\left(x^{T}\left(G+\rho^{2} H+Q+L^{T} R L\right) x+u^{T} R u+\rho^{2} v^{T} v\right) d t
$$

is minimum, where $\rho$ is some positive constant. The matrices $\mathrm{G} \geq 0$ and $\mathrm{H} \geq 0$ are given as:

$$
\begin{aligned}
& G=\inf \left\{\begin{array}{l}
G^{\prime}:(\forall p \in P), \\
G^{\prime} \geq\left(A(p)-A\left(p_{0}\right)\right)^{T} B^{+T} B^{+}\left(A(p)-A\left(p_{0}\right)\right)
\end{array}\right\} \\
& H=\inf \left\{\begin{array}{l}
H^{\prime}:(\forall p \in P), \\
H^{\prime} \geq r^{2}\left(A(p)-A\left(p_{0}\right)\right)^{T}\left(A(p)-A\left(p_{0}\right)\right)
\end{array}\right\}
\end{aligned}
$$

and the solution is obtained through the generalized Ricatti equation:

$$
A^{T} S+S A-S B R^{-1} B^{T} S+Q^{\prime}=0
$$

Where

$$
Q^{\prime}=Q+G+\rho^{2} H+L^{T} R L
$$

It can be shown that for $\dot{V}(x)<0$ we must have $Q+L^{T} R L-2 \rho^{2} \operatorname{diag}\left\{z_{i}\right\}^{T} \operatorname{diag}\left\{z_{i}\right\}>0$ that is

$\dot{x}=A(p) x+B \operatorname{diag}\left\{k_{i}\right\} x$ is asymptotically stable for all admissible uncertainties, and $\mathrm{u}=\operatorname{diag}\left\{\mathrm{k}_{\mathrm{i}}\right\} \mathrm{x}$ is a solution to the robust decentralised problem. (See the appendix).

A general procedure to handle this kind of problems is the following:

1. Set $\mathrm{L}=0$ in equation (11) or equation (14), and solve for the robust control problem without constraints.

2. Determine $\mathrm{L}=\mathrm{F}(\mathrm{K})$ for the chosen constraint.

3. Solve the Ricatti equation (equation (11), or equation (14)).

4. Test for convergence. For example, two consecutive values for the cost functional being less than a certain small positive value.

5. If 4 is not satisfied, go to step 2 with the calculated value for $\mathrm{P}$ from step 3 .

6. Determine the feasible gain $K \in \Omega$ through.

$$
K=R^{-1} B^{T} S-L
$$

\section{Example 1. Matched Uncertainty}

As an example of robust decentralised control for a matched uncertainty the linear model of a spring coupled pendula is presented in figure 1 [3]. The uncertainties are assumed to be the position of the spring along the rod, $\mathrm{h}$, and its stiffness, $\mathrm{k}$. It is known that the mathematical model of the pendula is given by: 


$$
\begin{aligned}
& \mathrm{ML}^{2} \frac{\partial^{2} \theta_{1}}{\partial t^{2}}=-\operatorname{MgLsin} \theta_{1}+\mathrm{hk}\left(\frac{\mathrm{h}}{\mathrm{L}}\right)\left(\mathrm{x}_{2}-\mathrm{x}_{1}\right) \\
& \mathrm{ML}^{2} \frac{\partial^{2} \theta_{2}}{\partial t^{2}}=-\operatorname{MgLsin} \theta_{2}+\mathrm{hk}\left(\frac{\mathrm{h}}{\mathrm{L}}\right)\left(\mathrm{x}_{2}-\mathrm{x}_{1}\right) .
\end{aligned}
$$

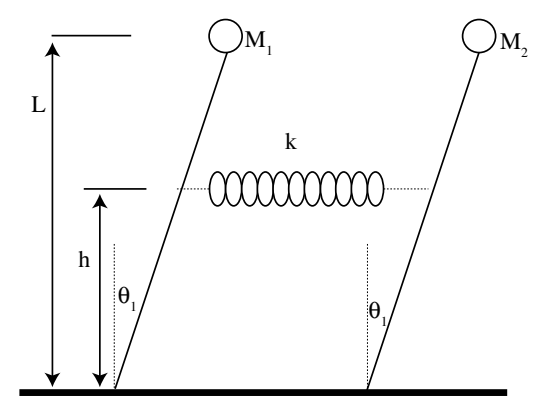

Figure 1. Spring Coupled Inverted Pendula.

Where g represents gravity acceleration and the meaning of the rest of the variables are evident from the figure. The uncertain values for $\mathrm{h}$ and $\mathrm{k}$ belong to a given interval as shown:

$$
\begin{aligned}
& h \in\left[\begin{array}{ll}
2, & 10
\end{array}\right] \\
& k \in\left[\begin{array}{ll}
0.5, & 2.5
\end{array}\right]
\end{aligned}
$$

Furthermore $\mathrm{L}=10 \mathrm{mg}, \mathrm{g}=9.81 \mathrm{~m} / \mathrm{seg}, \mathrm{ml}=0.5 \mathrm{~kg}$, $\mathrm{m} 2=0.6 \mathrm{~kg}$.

For a linear model of the pendula valid for the equilibrium point $(\pi, 0)$, figure 2 shows the migration of poles when the uncertain parameters vary within the given interval. The LQR closed loop poles migrate towards the imaginary axes as a function of the uncertain parameters. For a robust LQR solution it is evident that the real part of the poles are unaltered and the frequency excursions are minimal.

When the robust decentralised LQR strategy is applied, a real slightly dominant pole appears with no variation of its position for all the values of the parameters. The feedback gains and values for the cost functional in each case are:

Robust LQR feedback gain:

$$
\text { Kra }=\left[\begin{array}{llll}
0.8345 & 0.9814 & 0.9762 & 0.8402 \\
0.9307 & 0.8402 & 1.1828 & 1.2883
\end{array}\right]
$$

Robust LQR cost functional value:

$$
\mathrm{Jra}=0.2273
$$

Robust Decentralized Feedback gain:

$$
K r d a=\left[\begin{array}{cccc}
1.2295 & 1.6969 & 0 & 0 \\
0 & 0 & 1.5645 & 1.8840
\end{array}\right]
$$

Robust Decentralized cost functional value:

$$
\operatorname{Jrda}=0.3463
$$

The functional cost value is a $34.4 \%$ bigger than the robust LQR value so the decentralized solution is then a suboptimal one.

Figure 3 shows the results obtained from simulation for a non robust LQR control strategy for three different pair of parameters values:

$$
(\mathrm{k}, \mathrm{h}) \in[(\mathrm{a})(0.5,2.0),(\mathrm{b})(1.5,6.0),(\mathrm{c})(2.5,10.0)]
$$

State variables $\mathrm{x} 1$ and $\mathrm{x} 3$ represent angles $\theta_{1}$ and $\theta_{2}$ respectively. Simulation starts at $\mathrm{t}=0$, with initial condition $\theta_{1}=1 \mathrm{rad}$. It can be seen that for the value $\mathrm{h}=\mathrm{L}$ and maximum spring coefficient (figure 3.c) both pendulums act in phase opposition. Clearly the robustness is related to the speed of response.

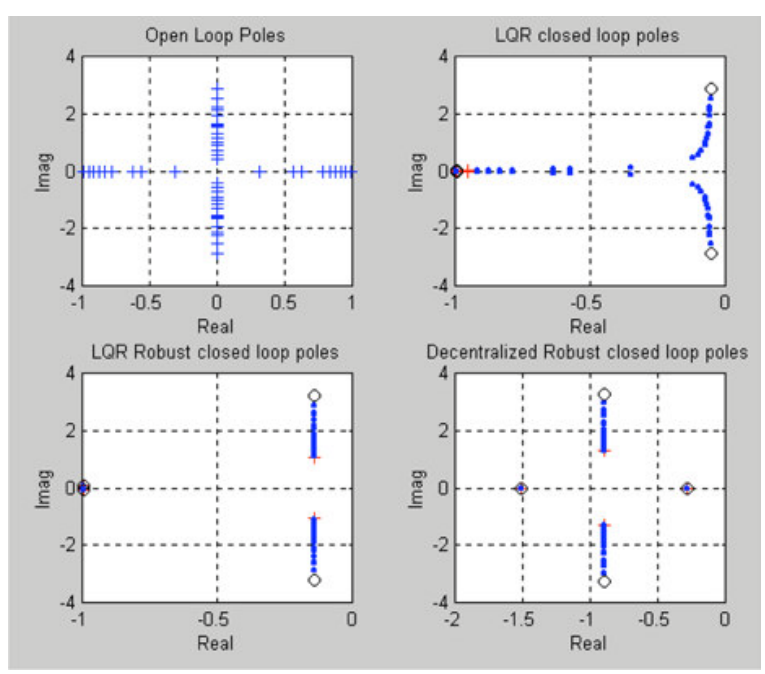

Figure 2. Pole migration for varying parameters Matched Uncertainty.

+ minimum value of parameters

0 maximum value of parameters.

The Robust LQR and the Decentralised Robust solutions (figure 4 and figure 5) are much faster and less oscillatory. It is clear from figure 5 that the decentralised robust solution corresponds to an almost dominant real pole. For the solution of the Riccati equation the weighing matrix Q was determined as comparable to the F matrix for the matched uncertainty case and matrix $\mathrm{R}$ was set as diagonal with values equal to 0.1 . 


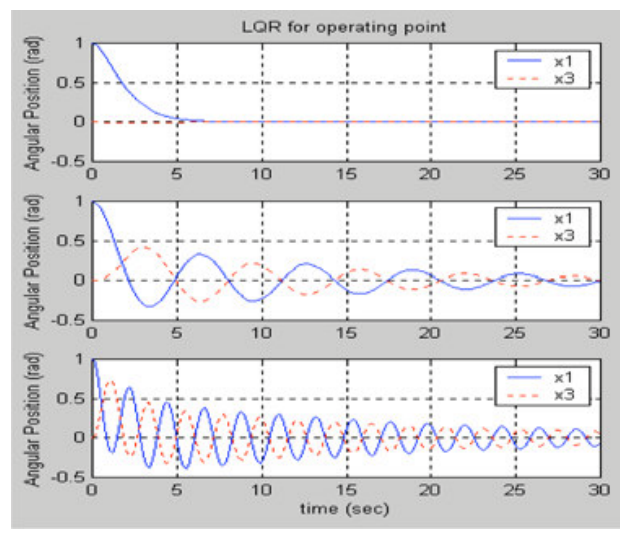

(a)

Figure 3. Non robust LQR control strategy three different values of $(\mathrm{k}, \mathrm{h})$.

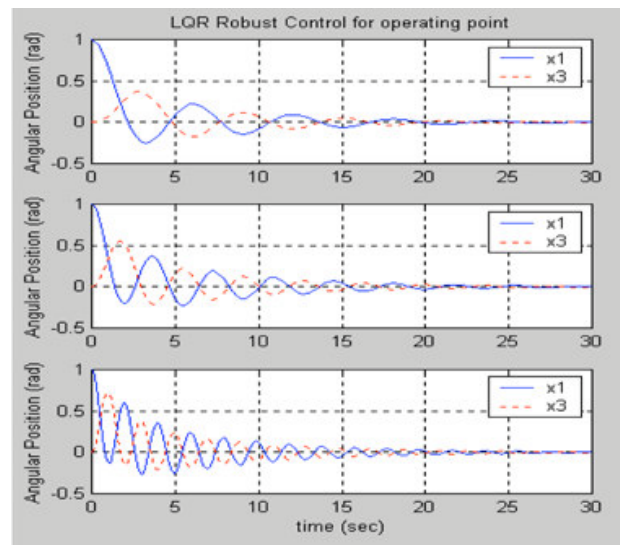

Figure 4. Robust LQR strategy and three different values of $(k, h)$.

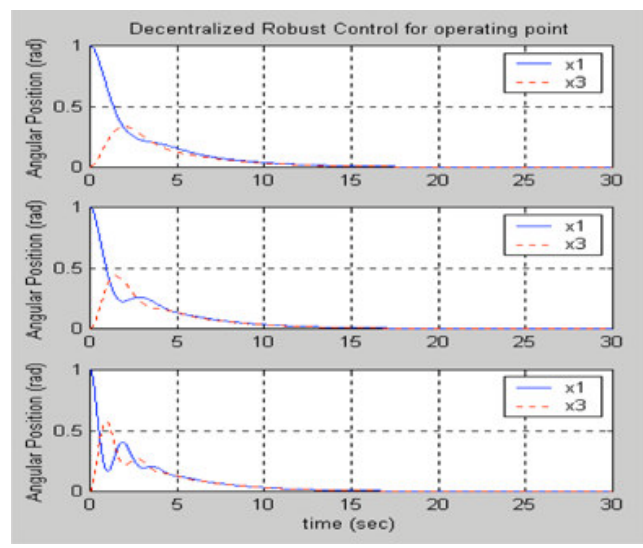

Figure 5. Robust decentralised LQR strategy for three different values of $(\mathrm{k}, \mathrm{h})$.

\section{Example 2. Unmatched Uncertainty}

As an example of robust decentralised control for an unmatched uncertainty, the linear model of the same inverted coupled pendula but with an altered matrix B was used. The results obtained are as follows (see figure 6).

Clearly the solution to the decentralised robust case shows how the real part of the dominant poles stays almost constant but close to the imaginary axes if compared to the robust LQR solution. The simulation results for the LQR, Robust LQR and Decentralised Robust LQR are shown in figure 7 , figure 8 and figure 9 , respectively.

From figure 7 and figure 8 it is seen that the LQR solution is faster and with less frequency excursion than the robust case. Nonetheless they are almost comparable. For the decentralised robust solution we have a big difference in response speed and frequency excursion, even though they are almost constant for varying values of the pair $(\mathrm{k}, \mathrm{h})$.

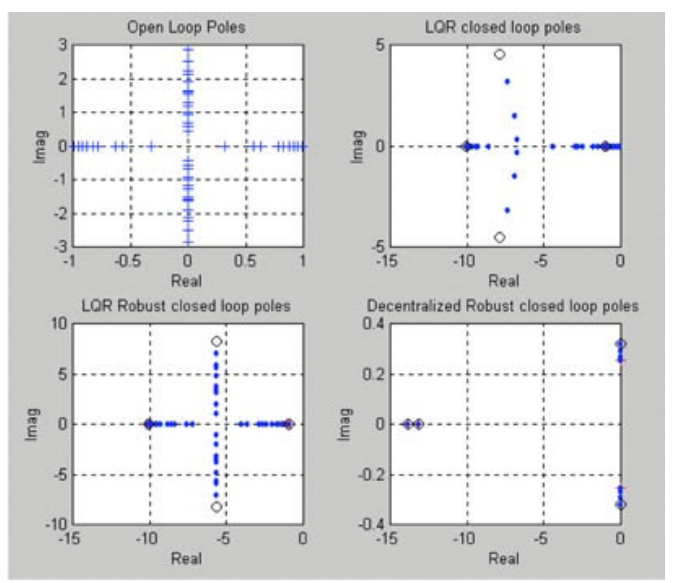

Figure 6. Pole migration for varying Parameters. Unmatched Uncertainty. + minimum value of parameters 0 maximum value of parameters

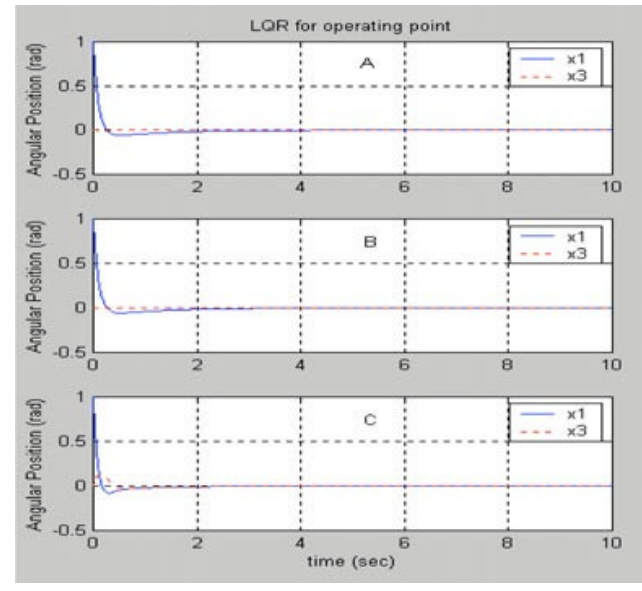

Figure 7. LQR response for three different values for the pair $(\mathrm{k}, \mathrm{h})$. 


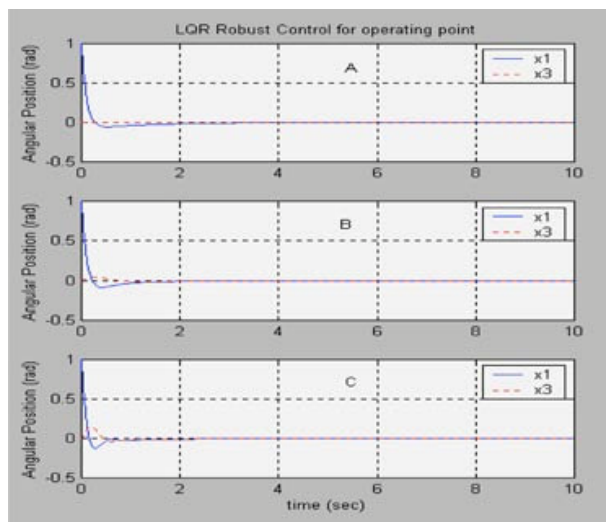

Figure 8. Robust LQR for three different values of the pair $(\mathrm{k}, \mathrm{h})$.

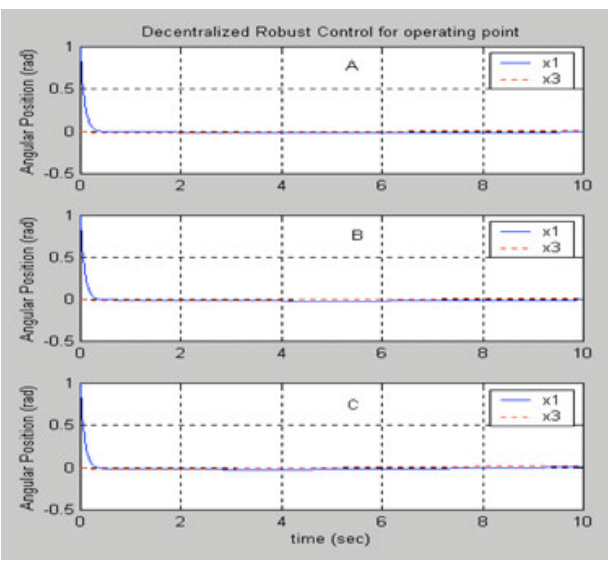

Figure 9. Robust Decentralised solution for three different values of the pair $(\mathrm{k}, \mathrm{h})$.

The values of the $\mathrm{L}$ matrix, $\mathrm{H}$ and $\mathrm{G}$ matrices and the design parameters rho, beta and $\mathrm{r}$ for the unmatched uncertainty case are as follows:

$L=\left[\begin{array}{cccc}0 & 0 & -0.1692 & 35.8924 \\ -0.1692 & 40.0509 & 0 & 0 \\ 0 & 0 & 0 & 0 \\ -0.0338 & 0 & 0.5006 & 0.0460 \\ 0 & 0 & 0 & 0 \\ 0.4487 & 0 & 0.0534 & 0\end{array}\right]$

$G_{r}=\left[\begin{array}{llll}0 & 0 & 0 & 0 \\ 0 & 0 & 0 & 0 \\ 0 & 0 & 0 & 0\end{array}\right]$

$H_{r}=\left[\begin{array}{cccc}1.0844 & 0 & -1.0844 & 0 \\ 0 & 0 & 0 & 0 \\ -1.0844 & 0 & 1.0844 & 0 \\ 0 & 0 & 0 & 0\end{array}\right]$

$\mathrm{rho}=2$, beta $=10$ and $\mathrm{r}=20$.
The functional cost values are :

Robust LQR: Jrna $=120.5972$

Decentralised Robust LQR: Jrdna $=539.3480$

Robust Feedback Gain for controls $\mathrm{u}$ and $\mathrm{v}$ is:

Krna $=\left[\begin{array}{cccc}11.0211 & 0.1324 & -0.1228 & 9.5697 \\ -0.1228 & 9.6874 & 11.2020 & 1.8669 \\ 0 & 0 & 0 & 0 \\ 0.0017 & 1.2650 & 0.1211 & -0.0087 \\ 0 & 0 & 0 & 0 \\ 0.1196 & -0.0087 & 0.0233 & 1.4722\end{array}\right]$

Decentralised Robust Feedback Gain for controls $\mathrm{u}$ and $\mathrm{v}$ is

$$
\text { Krdna }=\left[\begin{array}{cccc}
13.0989 & -2.7033 & 0 & 0 \\
0 & 0 & 13.9197 & 4.2731 \\
0 & 0 & 0 & 0 \\
0 & 6.5336 & 0 & 0 \\
0 & 0 & 0 & 0 \\
0 & 0 & 0 & 6.6123
\end{array}\right]
$$

\section{CONCLUSIONS}

A decentralised robust optimal control approach accounting for matched and unmatched uncertainties has been presented. The simulation results obtained from application of the methodology show that the approach gives good results. To the authors knowledge the optimal control approach to robust control design considering constraints as local states feedback for local control has not been reported yet. Work is under way to include output feedback or local outputs feedback for local control and robust compensators synthesis using this approach.

\section{ACKNOWLEDGMENTS}

The authors acknowledge the support given by Universidad Católica de Valparaíso (Valparaíso, Chile), through grants for projects \#204.704/2004 and \#204.708/2005.

\section{REFERENCES}

[1] F.Lin. "Robust Control Design: An Optimal Control Approach". AFI Press. 1997. 
[2] H.E. Peña. "Power System Stabilizer Design via Structurally Constrained Optimal Control". Electric Power System Research. 33, pp. 33-40. 1995.

[3] J.C. Geromel. "Methods and Techniques for Decentralized Control Systems: Analysis and Design”. Ed CLUP, Milano, Italy. 1987.

[4] A. Fischman, A.S. Bazanella and A.S.E. Silva. "Robust Decentralized Control Applied to Power System Stabilizer Design". IFAC Symposium on Robust Control Design. Río de Janeiro, Brasil. Section TM-B. Sept. 1994.

[5] A.S. Bazanella and C.C. Paim. "Robust Design of Damping Controllers in Power Systems". IEEE Power Tech'99 Conference. Budapest, Hungary. Paper BPT99-312-12. August 29-September 2, 1999.

[6] D. Rerkpreedapong, A. Hasanovic and A. Feliachi. "Robust Load Frequency Control Using Genetic Algorithms and Linear Matrix Inequalities". IEEE Transactions on Power Systems. Vol. 18 N², pp. 855-861. Mayo 2003.

[7] S.G. Wang, H.Y. Yeh and N. Roschke. "Robust Control for Structural Systems with Parametric and Unstructured Uncertainties". Proceedings of the American Control Conference. Arlington, VA, pp. 1109-1114. Junio 25-27, 2001.

\section{APPENDIX}

\section{Theorem 2 [1]}

Choosing $r$ and $\rho$ such that

$$
Q+L^{T} R L-2 \rho^{2} Z^{T} Z>0
$$

(positive definite), then the solution

$$
\mathrm{u}=\operatorname{diag}\left\{\mathrm{k}_{\mathrm{i}}\right\} \mathrm{x}
$$

is a solution to the robust decentralised problem.

Proof: $\left[A\left(p_{0}\right), B\right]$ is stabilizable, and $\mathrm{G} \geq 0, \mathrm{H} \geq 0$. The solution to the LQR problem exists. Denote the solution as $\mathrm{u}=\operatorname{diag}\left\{\mathrm{k}_{\mathrm{i}}\right\}$ and $\mathrm{v}=\operatorname{diag}\left\{\mathrm{z}_{\mathrm{i}}\right\}$. We want to prove that $\mathrm{u}=\operatorname{diag}\left\{\mathrm{k}_{\mathrm{i}}\right\}$ is a solution to the robust decentralised control problem. That is,

$$
\dot{x}=A(p) x+B \operatorname{diag}\left\{k_{i}\right\} x
$$

is asymptotically stable for all $\mathrm{p} \in \mathrm{P}$.

Define

$$
V\left(x_{0}\right)=\min _{u \in \mathcal{R}^{m}} \int_{0}^{\infty}\left(x^{T}\left(G+\rho^{2} H+Q\right) x+u^{T} R u+\rho^{2} v^{T} v\right) d t
$$

to be the minimum cost of the optimal control from some initial state $\mathrm{x}_{0}$. The Hamilton-Jacobi-Bellman equation gives

$$
\min _{u \in \Re^{m}}\left(x^{T}\left(G+\rho^{2} H+Q\right) x+u^{T} R u+\rho^{2} v^{T} v+V_{x}^{T} \dot{x}=0\right.
$$

Since $\mathrm{u}=\operatorname{diag}\left\{\mathrm{k}_{\mathrm{i}}\right\}$ and $\mathrm{v}=\operatorname{diag}\left\{\mathrm{z}_{\mathrm{i}}\right\}$ is the optimal control

$$
\begin{aligned}
& x^{T}\left(G+\rho^{2} H+Q\right) x+u^{T} R u+\rho^{2} v^{T} v+V_{x}^{T} \dot{x}=0 \\
& 2 x^{T} \operatorname{diag}\left\{k_{i}\right\}^{T}+V_{x}^{T} B=0 \\
& 2 \rho^{2} x^{T} Z^{T}+V_{x}^{T} r^{-1}\left(I-B B^{+}\right)=0
\end{aligned}
$$

where $\mathrm{B}^{+}$is the pseudo inverse of $\mathrm{B}$.

Clearly $\mathrm{V}(\mathrm{x})>0$ for $\mathrm{x} \neq 0$ and $\mathrm{V}(\mathrm{x})=0$ for $\mathrm{x}=0$.

Since $\dot{V}(x)<0$ for $\mathrm{x} \neq 0$,we have

$$
\begin{aligned}
\dot{V}(x)= & V_{x}^{T} \dot{x}=V_{x}^{T}\left(A(p) x+B \operatorname{diag}\left\{k_{i}\right\} x\right) \\
=V_{x}^{T} & \left(A(p) x+A\left(p_{0}\right) x-A\left(p_{0}\right) x+B \operatorname{diag}\left\{k_{i}\right\} x\right. \\
& \left.+r^{-1}\left(I-B B^{+}\right) \operatorname{diag}\left\{z_{i}\right\} x-r^{-1}\left(I-B B^{+}\right) \operatorname{diag}\left\{z_{i}\right\} x\right) \\
=V_{x}^{T} & \left(A\left(p_{0}\right) x+B \operatorname{diag}\left\{k_{i}\right\} x+r^{-1}\left(I-B B^{+}\right) \operatorname{diag}\left\{z_{i}\right\} x\right) \\
& +V_{x}^{T}\left(\left[A(p)-A\left(p_{0}\right)\right] x-r^{-1}\left(I-B B^{+}\right) \operatorname{diag}\left\{z_{i}\right\} x\right)
\end{aligned}
$$

From equation (15a)

$$
\begin{gathered}
V_{x}^{T}\left(A\left(p_{0}\right) x+B \operatorname{diag}\left\{k_{i}\right\} x+r^{-1}\left(I-B B^{+}\right) \operatorname{diag}\left\{z_{i}\right\} x\right)= \\
-\left[x^{T}\left(G+\rho^{2} H+Q+L^{T} R L\right) x+u^{T} R u+\rho^{2} v^{T} v\right.
\end{gathered}
$$

but

$$
\begin{aligned}
{[A(p)} & \left.-A\left(p_{0}\right)\right] x \\
& =B B^{+}\left[A(p)-A\left(p_{0}\right)\right] x+\left(I-B B^{+}\right)\left[A(p)-A\left(p_{0}\right)\right] x
\end{aligned}
$$


then

$\dot{V}(x)=-\left[x^{T} G x+x^{T} \rho^{2} H x+x^{T}\left(Q+L^{T} R L\right) x+u^{T} R u+\rho^{2} v^{T} v\right]$

$+V_{x}^{T}\left(B B^{+}\left[A(p)-A\left(p_{0}\right)\right] x+\left(I-B B^{+}\right)\left[A(p)-A\left(p_{0}\right)\right] x\right.$

$\left.-r^{-1}\left(I-B B^{+}\right) \operatorname{diag}\left\{z_{i}\right\} x\right)$

and because from equation (15b)

$V_{x}^{T}=-2 x^{T} \operatorname{diag}\left\{k_{i}\right\}^{T} R B^{+}$

and from equation $(15 \mathrm{c})$

$2 \rho^{2} x^{T} Z^{T}=-V_{x}^{T} r^{-1}\left(I-B B^{+}\right)$

Knowing that $\mathrm{B}^{+} \mathrm{BB}^{+}=\mathrm{B}^{+}$, it follows that

$$
\begin{aligned}
\dot{V}(x) & =-x^{T} G x-x^{T} \rho^{2} H x-x^{T}(Q+L R L) x-x^{t} \operatorname{diag}\left\{k_{i}\right\}^{T} \operatorname{Rdiag}\left\{k_{i}\right\} \\
- & \rho^{2} x^{T} \operatorname{diag}\left\{z_{i}\right\}^{T} \operatorname{diag}\left\{z_{i}\right\} x-2 x^{T} \operatorname{diag}\left\{k_{i}\right\}^{T} R B^{+}\left(A(p)-A\left(p_{0}\right)\right) x \\
+ & 2 \rho^{2} x^{T} \operatorname{diag}\left\{z_{i}\right\}^{T} \operatorname{diag}\left\{z_{i}\right\} x
\end{aligned}
$$

\section{Clearly}

$$
\begin{aligned}
& 2 x^{T} \operatorname{diag}\left\{k_{i}\right\}^{T} R B^{+}\left(A(p)-A\left(p_{0}\right)\right) x= \\
& 2 \rho^{2} x^{T} Z^{T} r Z X+2 x^{T} \operatorname{diag}\left\{k_{i}\right\}^{T} R B^{+}\left(A(p)-A\left(p_{0}\right)\right) x
\end{aligned}
$$

so

$$
\begin{aligned}
\dot{V}(x)= & -x^{T} G x-x^{T} \rho^{2} H x-x^{T}(Q+L R L) x \\
& -x^{t} \operatorname{diag}\left\{k_{i}\right\}^{T} R \operatorname{diag}\left\{k_{i}\right\}-\rho^{2} x^{T} \operatorname{diag}\left\{z_{i}\right\}^{T} \operatorname{diag}\left\{z_{i}\right\} x \\
& -2 \rho^{2} x^{T} Z^{T} r Z x-2 x^{T} \operatorname{diag}\left\{k_{i}\right\}^{T} R B^{+}\left(A(p)-A\left(p_{0}\right)\right) x \\
& +2 \rho^{2} x^{T} \operatorname{diag}\left\{z_{i}\right\}^{T} \operatorname{diag}\left\{z_{i}\right\} x
\end{aligned}
$$

but

$$
\begin{aligned}
- & x^{t} \operatorname{diag}\left\{k_{i}\right\}^{T} R \operatorname{diag}\left\{k_{i}\right\}-2 x^{T} \operatorname{diag}\left\{k_{i}\right\}^{T} R B^{+}\left(A(p)-A\left(p_{0}\right)\right) x= \\
& -x^{t} \operatorname{diag}\left\{k_{i}\right\}^{T} R \operatorname{diag}\left\{k_{i}\right\}-x^{T}\left(\operatorname{diag}\left\{k_{i}\right)^{\mathrm{T}} \mathrm{RB}^{+}\left(A(p)-A\left(p_{0}\right)\right)\right. \\
& +\left(\operatorname{diag}\left\{k_{i}\right)^{\mathrm{T}}{ }^{+}\left(A(p)-A\left(p_{0}\right)\right)\right)^{T} x+x^{T}\left(B^{+}\left(A(p)-A\left(p_{0}\right)\right)\right)^{T} \\
& B^{+}\left(A(p)-A\left(p_{0}\right)\right) x \\
= & -x^{T}\left[\operatorname{diag}\left\{k_{i}\right\}^{T} R-B^{+}\left(A(p)-A\left(p_{0}\right)\right)\right]^{\mathrm{T}} \\
& {\left[\operatorname{diag}\left\{k_{i}\right\}^{T} R-B^{+}\left(A(p)-A\left(p_{0}\right)\right)\right] } \\
& +x^{T}\left(B^{+}\left(A(p)-A\left(p_{0}\right)\right)\right)^{T}\left(B^{+}\left(A(p)-A\left(p_{0}\right)\right)\right) x \\
\leq & x^{T}\left(B^{+}\left(A(p)-A\left(p_{n}\right)\right)\right)^{T}\left(B^{+}\left(A(p)-A\left(p_{n}\right)\right)\right) x \\
\text { and } & -\rho^{2} x^{T} \operatorname{diag}\left\{z_{i}\right\}^{T} \operatorname{diag}\left\{z_{i}\right\} x-2 \rho^{2} x^{T} Z^{T} r Z x= \\
& -x^{T} \rho^{2}\left(\operatorname{diag}\left\{z_{i}\right\}^{T} \operatorname{diag}\left\{z_{i}\right\}-2 \operatorname{diag}\left\{z_{i}\right\}^{T} r \operatorname{diag}\left\{z_{i}\right\}\right) x= \\
- & x^{T}\left(\rho^{2} \operatorname{diag}\left\{z_{i}\right\}^{T}-\rho^{2} \operatorname{rdiag}\left\{z_{i}\right\}\right)^{T}\left(\rho^{2} \operatorname{diag}\left\{z_{i}\right\}^{T}-\rho^{2} r \operatorname{diag}\left\{z_{i}\right\}\right) x \\
\leq & \rho^{2} x^{T} r \operatorname{diag}\left\{z_{i}\right\}^{T} \operatorname{rdiag}\left\{z_{i}\right\} x=\rho^{2} x^{T} r^{2} \operatorname{diag}\left\{z_{i}\right\}^{T} \operatorname{diag}\left\{z_{i}\right\} x \\
\leq & \rho^{2} x^{T} H x
\end{aligned}
$$

Clearly then if $\dot{V}(x)<0$ we must have

$Q+L^{T} R L-2 \rho^{2} \operatorname{diag}\left\{z_{i}\right\}^{T} \operatorname{diag}\left\{z_{i}\right\}>0$

that is $\dot{x}=A(p) x+B \operatorname{diag}\left\{k_{i}\right\} x$ is asymptotically stable for all admissible uncertainties, and

$$
\mathrm{u}=\operatorname{diag}\left\{\mathrm{k}_{\mathrm{i}}\right\} \mathrm{x}
$$

is a solution to the robust decentralised problem. 